\title{
AVALIAÇÃO DAS CONDIÇÕES HIGIÊNICO-SANITÁRIAS DE RESTAURANTES COMERCIAIS DO TIPO SELF-SERVICE DA REGIÃO CENTRAL DO RIO GRANDE DO SUL ${ }^{1}$
}

\author{
EVALUATION OF THE HYGIENIC-SANITARY CONDITIONS OF \\ COMMERCIAL RESTAURANTS OF THE SELF-SERVICE TYPE OF \\ THE CENTRAL REGION OF RIO GRANDE DO SUL
}

\author{
Bruna Lago Tagliapietra ${ }^{2}$ e Andrea Pissatto Peres ${ }^{3}$
}

\section{RESUMO}

Uma das principais preocupações da vigilância sanitária são os alimentos. É necessário manter a fiscalização sobre os estabelecimentos que produzem e comercializam alimentos industrializados e in natura, bem como aqueles que servem refeições comerciais, a fim de garantir segurança alimentar aos consumidores. Sendo assim, o objetivo deste trabalho foi avaliar as condições higiênico-sanitárias de restaurantes comerciais de uma cidade da região central do Rio Grande do Sul (RS), com base na legislação estadual vigente. Participaram do estudo dois restaurantes com atendimento a um público aproximado de 50 pessoas/dia. Os restaurantes foram avaliados quanto à adequação às boas práticas por meio da aplicação da lista de verificação, que é parte integrante da Portaria Estadual $n^{0} 78$, de 15 de setembro de 2009 e classificados segundo o grau de risco que representam à segurança dos alimentos. De acordo com a lista de verificação aplicada, a classificação de ambos os restaurantes comerciais foi insatisfatória para a produção de alimentos seguros. Nenhum dos doze itens avaliados atingiu o grupo 1 , considerado bom. No que se refere a documentação dos restaurantes, ambos apresentaram $100 \%$ de inadequação. A adesão às boas práticas se tornaria uma ferramenta viável para melhorar a qualidade das refeições produzidas pelo restaurante, garantindo um alimento seguro, sem risco de danos para a saúde do consumidor.

Palavras-chave: Legislação sobre Alimentos. Boas Práticas de Fabricação. Doenças Transmitidas por Alimentos.

\section{ABSTRACT}

One of the main concerns of sanitary surveillance is food. Surveillance of establishments producing and marketing industrialized and fresh foods and those serving commercial meals should be maintained in order to ensure food safety for consumers. Therefore, the objective of this study was to evaluate the hygienicsanitary conditions of commercial restaurants in a city in the central region of Rio Grande do Sul (RS), based on the state legislation in force. Two restaurants attended a study of approximately 50 people / day. The restaurants were evaluated for compliance with good practices through the application of the checklist, which is an integral part of State Ordinance No. 78, dated September 15, 2009 and classified according to the degree of risk they represent to food safety. According to the checklist applied, the classification of both commercial restaurants was unsatisfactory for the production of safe food. None of the twelve evaluated items reached group 1, considered good. Regarding the documentation of the restaurants, both were 100\% inadequate.

\footnotetext{
${ }^{1}$ Trabalho de conclusão de especialização.

${ }^{2}$ Autora, nutricionista. E-mail: bruna_tagliapietra@hotmail.com

${ }^{3}$ Orientadora, docente no Centro Universitário Internacional. E-mail: andrea@linhalivre.com.br
} 
Adherence to good practices would become a viable tool to improve the quality of meals produced by the restaurant, ensuring a safe food with no risk of harm to consumer health.

Keywords: Food legislation. Foodborne illness. Good Manufacturing Practice.

\section{INTRODUÇÃO}

O consumo de alimentos fora de casa, seja por questões sociais ou por necessidades vinculadas à rotina e ao estilo de vida atual, tem contribuído para o crescimento dos serviços de alimentação. Com o aumento no número de refeições oferecidas fora do lar, torna-se grande a preocupação com a qualidade dos alimentos oferecidos aos usuários (SILVA et al., 2015). No Brasil, cerca de 62,7\% das refeições são realizadas fora de casa, geralmente no local de trabalho (ABERC, 2019).

A alimentação é uma das atividades mais importantes do ser humano, tanto por razões biológicas quanto pelas questões sociais e culturais que envolvem o ato de comer. Alimentar-se engloba vários aspectos, que vão desde a produção dos alimentos até a sua transformação em refeições e disponibilização às pessoas (PROENÇA et al., 2015). No Brasil, a ANVISA (Agência Nacional de Vigilância Sanitária) é o órgão regulatório, responsável por criar normas e regulamentos e dar suporte para todas as atividades no ramo de alimentação. De acordo com a ANVISA, todo estabelecimento onde o alimento é manipulado, preparado, armazenado e/ou exposto à venda é considerado um serviço de alimentação (AKUTSU et al., 2005).

Dentre as modalidades de serviços de alimentação, destacam-se as Unidades de Alimentação e Nutrição (UANs), considerada a unidade de trabalho ou órgão de uma empresa que desempenha atividades relacionadas à alimentação e à nutrição, onde são desenvolvidas todas as atividades técnico-administrativas necessárias para a produção de alimentos e refeições, até a sua distribuição (CONSELHO FEDERAL DE NUTRICIONISTAS, 2005). O objetivo principal das UANs é fornecer alimentação nutricionalmente equilibrada, a fim de preservar ou recuperar a saúde dos seus consumidores. Desta forma, é intrínseco às atividades das UANs o conceito da inocuidade dos alimentos, representado pela qualidade higiênico-sanitária e produção de alimento seguro (MELLO et al., 2013). As obrigações legais, bem como a competitividade do mercado de alimentação e as exigências dos consumidores, impulsionaram os serviços de alimentação na busca de ferramentas que auxiliassem na implantação e no controle de inocuidade de seus produtos (SACCOL et al., 2009).

As Boas Práticas de Fabricação (BPF) são normas de procedimentos para atingir um determinado padrão de identidade e qualidade de um produto ou serviço na área de alimentos. A eficácia e efetividade na aplicação dessas normas devem ser avaliadas através de inspeções, constituindo medidas preventivas para o controle dos perigos (BRASIL, 2004). Para diagnosticar preliminarmente a adesão às boas práticas, a legislação brasileira indica a aplicação de lista de verificação, cujos resultados permitem identificar pontos de não conformidade e traçar ações corretivas (GENTA et al., 2005). 
A identificação de itens de verificação críticos pode servir de complemento ao diagnóstico da adequação às boas práticas em UANs, pois esses itens podem auxiliar na prevenção da ocorrência de surtos (ALMEIDA et al., 2009). Muitos surtos são ocasionados por Doenças Transmitidas por Alimentos (DTAs); elas estão relacionadas ao consumo de alimentos contendo bactérias patogênicas, em refeições preparados nas residências, restaurantes comerciais e nas cozinhas industriais (MARCHI et al., 2011). As condições higiênicas dos locais de produção e a manipulação dos alimentos interferem na qualidade microbiológica dos mesmos, por serem consideradas pontos de contaminação; por sua vez, os manipuladores são, frequentemente, disseminadores de agentes patogênicos (ZANDONADI et al., 2007).

Em virtude dessas questões, a ANVISA publicou a Resolução de Diretoria Colegiada (RDC) $\mathrm{n}^{\circ} 216$, de 15 de setembro de 2004, que está em vigor desde março de 2005, na qual aprova o Regulamento Técnico de Boas Práticas para Serviços de Alimentação. Considerando a necessidade constante de aperfeiçoamento das ações de controle sanitário na área de alimentos, a Secretaria do Estado do Rio Grande do Sul instituiu a Portaria Estadual no 78, de 15 de setembro de 2009, que aprova a Lista de Verificação em Boas Práticas para Serviços de Alimentação, que tem como objetivo estabelecer procedimentos de boas práticas para serviços de alimentação, a fim de garantir as condições higiênico-sanitárias do alimento preparado.

Com base no exposto, o objetivo deste trabalho foi avaliar as condições higiênico-sanitárias de restaurantes comerciais de uma cidade da região central do Rio Grande do Sul (RS), com base na legislação estadual vigente.

\section{MÉTODOS}

Participaram do estudo dois restaurantes comerciais com sistema de distribuição self-service, localizados na região central do Rio Grande do Sul, com atendimento a um público aproximado de 50 pessoas/dia, servindo apenas almoço, com horário de funcionamento das $11 \mathrm{~h} 30 \mathrm{~min}$ às $14 \mathrm{~h} 00 \mathrm{~min}$. Ambos os restaurantes contavam, no período da pesquisa, com três funcionários na área de manipulação de alimentos e um na área administrativa. Para o presente estudo, os restaurantes foram identificados como RA e RB. Os restaurantes foram avaliados quanto à adequação às boas práticas por meio da aplicação da lista de verificação, que é parte integrante da Portaria Estadual $n^{\circ} 78$, de 15 de setembro de 2009 (RIO GRANDE DO SUL, 2009).

A lista de verificação aplicada no presente estudo contemplou 152 itens de questionamentos categorizados em 12 grupos de avaliação: (1) Edificação, instalações, equipamentos, móveis e utensílios; (2) Higienização de instalações, equipamentos, móveis e utensílios; (3) Controle integrado de pragas; (4) Abastecimento de água; (5) Manejo de resíduos; (6) Manipuladores; (7) Matérias-primas, ingredientes e embalagens; (8) Preparação do alimento; (9) Armazenamento e transporte do alimento preparado; (10) Exposição ao consumo do alimento preparado; (11) Documentação e registro; (12) Responsabilidade técnica. 
O preenchimento da lista ocorreu no próprio restaurante, por meio de observação direta e registro fotográfico do funcionamento, observação das instalações físicas, relatos de funcionários e análise documental. As opções de respostas para o preenchimento da lista de verificação foram registradas como "Conforme" (C), quando o restaurante atendeu ao item observado, "Não Conforme" (NC), quando o restaurante apresentou não-conformidade para o item observado e "Não se Aplica" (NA), quando o item foi considerado não pertinente a realidade do local pesquisado. Os itens, cuja resposta foi a opção: "Não se Aplica”, não foram estatisticamente avaliados.

Os estabelecimentos foram classificados segundo o grau de risco que representam à segurança dos alimentos. A porcentagem de adequação foi calculada com base na RDC n⿳ 275 de 2002, onde se determinou que os estabelecimentos que apresentassem percentual entre 0 e $50 \%$ pertenceriam ao grupo 3 = Deficiente; entre 51 e $75 \%$ ao grupo 2 = Regular; e os que obtivessem de 76 a $100 \%$ pertenceriam ao grupo $1=$ Bom (BRASIL, 2002).

Os estabelecimentos concederam prévia autorização para a realização da pesquisa e as visitas ocorreram em horário de funcionamento com conhecimento de toda a equipe.

Os resultados foram analisados por meio de análise descritiva e apresentados em porcentagem, conforme a RDC nº 275 (BRASIL, 2002).

\section{RESULTADOS E DISCUSSÃO}

A lista de verificação aplicada neste estudo contemplou 152 itens, divididos em 12 grupos. A tabela 1 apresenta os resultados da aplicação da lista de verificação no restaurante RA e RB.

Tabela 1 - Classificação dos restaurantes (RA e RB) quanto aos grupos de verificação que compõem a Portaria n $78,2009 / \mathrm{RS}$, Brasil.

\begin{tabular}{|c|c|c|c|c|c|c|c|c|c|}
\hline & \multirow{3}{*}{ Grupos de verificação } & \multicolumn{6}{|c|}{ \% de adequação dos restaurantes } & \multirow{2}{*}{\multicolumn{2}{|c|}{ Classificação }} \\
\hline & & \multicolumn{2}{|c|}{$\mathrm{C}^{\mathrm{a}}$} & \multicolumn{2}{|c|}{$\mathrm{NC}^{\mathbf{b}}$} & \multicolumn{2}{|c|}{$\mathbf{N A}^{\mathbf{c}}$} & & \\
\hline & & RA & RB & RA & RB & RA & RB & RA & RB \\
\hline 1. & Edificação, instalações, equipamentos, móveis e utensílios & 47,0 & 62,3 & 44,2 & 37,7 & 8,8 & 0,0 & $\mathrm{D}$ & $\mathrm{D}$ \\
\hline 2. & $\begin{array}{l}\text { Higienização de instalações, equipamentos, móveis e } \\
\text { utensílios }\end{array}$ & 35,3 & 25,9 & 52,9 & 62,4 & 11,8 & 11,7 & $\mathrm{D}$ & $\mathrm{D}$ \\
\hline 3. & Controle integrado de pragas & 28,6 & 14,3 & 71,4 & 85,7 & 0,0 & 0,0 & $\mathrm{D}$ & $\mathrm{D}$ \\
\hline 4. & Abastecimento de água & 55,6 & 55,6 & 33,3 & 33,3 & 11,1 & 11,1 & $\mathrm{R}$ & $\mathrm{R}$ \\
\hline 5. & Manejo de resíduos & 66,7 & 66,7 & 33,3 & 33,3 & 0,0 & 0,0 & $\mathrm{R}$ & $\mathrm{R}$ \\
\hline 6. & Manipuladores & 33,3 & 26,6 & 66,7 & 73,4 & 0,0 & 0,0 & $\mathrm{D}$ & $\mathrm{D}$ \\
\hline 7. & Matérias-primas, ingredientes e embalagens & 25,0 & 25,0 & 75,0 & 75,0 & 0,0 & 0,0 & $\mathrm{D}$ & $\mathrm{D}$ \\
\hline 8. & Preparação do alimento & 26,9 & 38,5 & 73,1 & 61,5 & 0,0 & 0,0 & $\mathrm{D}$ & $\mathrm{D}$ \\
\hline 9. & Armazenamento e transporte do alimento preparado & - & - & - & - & 100 & 100 & & \\
\hline 10. & Exposição ao consumo do alimento preparado & 55,6 & 44,4 & 44,4 & 55,6 & 0,0 & 0,0 & $\mathrm{R}$ & $\mathrm{D}$ \\
\hline 11. & Documentação e registro & 0,0 & 0,0 & 100 & 100 & 0,0 & 0,0 & $\mathrm{D}$ & $\mathrm{D}$ \\
\hline 12. & Responsabilidade técnica & 0,0 & 0,0 & 100 & 100 & 0,0 & 0,0 & $\mathrm{D}$ & $\mathrm{D}$ \\
\hline
\end{tabular}

Legenda: ${ }^{\mathrm{a}}=$ Conforme, ${ }^{\mathrm{b}}=$ Não Conforme, ${ }^{\mathrm{c}}=$ Não se Aplica. $\mathrm{D}=$ Deficiente, $\mathrm{R}=$ Regular, $\mathrm{B}=\mathrm{Bom}$. 
No que se refere aos itens 1 e 2 da tabela 1 (respectivamente: Edificações, instalações, equipamentos, móveis e utensílios; Higienização de instalações, equipamentos, móveis e utensílios), ambos os estabelecimentos demonstraram não ter uma estrutura projetada para evitar cruzamentos no preparo dos alimentos, não há separação entre as diferentes atividades. O restaurante RA apresentou entre as principais inadequações as instalações elétricas, que se encontram expostas, o que dificulta a higienização. Os banheiros estavam inadequadamente localizados, não podendo ter comunicação direta com a área de produção, e também se observou que os equipamentos e utensílios não apresentavam uma adequada higienização. O processo de higienização é de extrema importância nos equipamentos de uma UAN, pois esses podem disseminar microrganismos ao ambiente e aos alimentos (LETHO et al., 2011).

No restaurante RB a porcentagem de adequação foi maior, os equipamentos e utensílios se apresentavam em estado adequado de higienização. No que se refere à manutenção programada periódica e registro das atividades, o estabelecimento apresentou conhecimento da exigência dessas práticas, mas, devido à escassez de recursos humanos, elas não eram realizadas. Uma dificuldade encontrada foi relacionada ao uso de esponjas e panos não descartáveis, dado que estes não eram trocados a cada 2 horas, sendo usados durante todo o turno de preparação do almoço, e também não eram higienizados de maneira adequada. Os equipamentos, móveis e utensílios que entram em contato com alimentos devem ser de materiais que não transmitam substâncias tóxicas, odores, nem sabores aos mesmos; devem ser mantidos em adequado estado de conservação, além de ser resistente à corrosão, bem como às repetidas operações de limpeza e desinfecção (BRASIL, 2004).

O item 3 da tabela 1 (Controle integrado de pragas) é muito importante em serviços de alimentação, visto que a presença de pragas apresenta um grande risco de transmissão de doença. Em ambos os restaurantes havia uma prevenção, armadilhas em locais estratégicos para evitar a entrada de pragas e vetores, porém não existiam registros de quem realizava as operações e nem a maneira como era realizada. O estabelecimento RA apresentava telas milimétricas nas janelas para impedir o acesso de pragas às instalações. As pragas constituem uma séria ameaça à inocuidade dos alimentos, portanto as edificações, as instalações, os equipamentos, os móveis e os utensílios devem ser livres de vetores e pragas. Deve existir um conjunto de ações eficazes e contínuas de controle, com o objetivo de impedir a atração, o abrigo, o acesso e/ou proliferação dos mesmos (BRASIL, 2004). Cabe ressaltar que, toda e qualquer aplicação de produto químico para o controle de pragas deve ser feita por empresa especializada, a qual deve apresentar laudo de cada serviço executado (TONDO; BARTZ, 2014).

Em relação ao item 4 da tabela 1 (Abastecimento de água), ambos apresentaram percentual de adequação de 55,6\%. Sabe-se que, além da poluição direta das fontes de água e dos sistemas de distribuição, as condições higiênico-sanitárias e conservação dos reservatórios também podem ser responsáveis pela veiculação de agentes patogênicos (MICHELINA et al., 2006). Foi observada a existência de registros da higienização do reservatório, datados e rubricados, porém não havia manutenção 
periódica da higienização dos reservatórios. Conforme estabelecido pela legislação, o reservatório de água deve ser higienizado, em intervalo máximo de 6 meses, devendo ser mantidos os registros das operações (BRASIL, 2004).

Dentre todos os itens da tabela 1, o item 5 (Manejo de resíduos) foi o que apresentou maior adequação em ambos os restaurantes. Verificou-se que os restaurantes apresentaram números suficientes de coletores de resíduos, conforme a especificação, não atendendo apenas ao item que diz respeito ao local de armazenamento dos resíduos descartados, onde utilizam lixeiras sem tampa que se encontram na frente do restaurante. Os resíduos devem ser frequentemente coletados e estocados em local fechado e isolado da área de preparação de alimentos, a fim de evitar focos de contaminação e atração de vetores e pragas urbanas, bem como evitar contaminação cruzada das preparações. É necessário adotar medidas apropriadas para remoção e armazenamento de resíduos produzidos nos estabelecimentos, evitando, assim, seu acúmulo (BRASIL, 2004).

O item 6 da tabela 1 (Manipuladores) apresentou baixa adequação em ambos os estabelecimentos, sabe-se que muitas Doenças Transmitidas por Alimentos ocorrem devido à contaminação por parte dos manipuladores durante a preparação e produção de alimentos, por isso esse é um item de extrema importância. Os manipuladores apresentavam-se em desacordo com relação ao uso de uniformes, adornos e higienização das mãos. Segundo a Portaria $n^{\circ} 78$, os funcionários devem vestir uniformes de cores claras, limpos e em adequado estado de conservação, proteção para cabelo cobrindo completamente os fios, não sendo permitido o uso de barba. As unhas devem estar curtas e sem esmaltes, pois, se estiverem grandes, podem permitir maior acúmulo de sujidades e microrganismo e, se estiverem pintadas, pedaços de esmalte podem cair sobre os alimentos. Além disso, durante a manipulação, devem ser retirados todos os objetos de adorno pessoal e maquiagem (BRASIL, 2004).

O restaurante RB realiza supervisão de saúde dos manipuladores e, quando necessário, os mesmos são afastados. Observou-se falta de cartazes de orientações aos manipuladores para correta higienização das mãos e demais hábitos higiênicos a serem seguidos. A falta de higienização das mãos é uma atitude de risco, uma vez que as mãos dos manipuladores podem ser foco de disseminação de doenças (LUES; TANDER, 2007). As mãos devem ser higienizadas toda vez que os manipuladores mudarem de atividades, visto que podem veicular vários patógenos alimentares, sendo a sua antissepsia um importante fator para a prevenção de surtos alimentares, os lavatórios devem ser exclusivos para higienização das mãos, em posições estratégicas em relação ao fluxo de produção, e os mesmos devem possuir sabonete líquido e produto antisséptico, toalhas de papel não reciclado ou outro sistema seguro de secagem das mãos; também é necessário coletor de papel acionado sem contato manual (BRASIL, 2004).

Em relação ao item 7 da tabela 1 (Matérias-primas, ingredientes e embalagens), os estabelecimentos apresentaram baixa adequação. Percebeu-se que o maior problema estava no controle de 
temperatura, já que o mesmo não era realizado e, se realizado, não era registrado. Muitos alimentos se encontravam armazenados em desacordo com as temperaturas indicadas pelo fabricante e/ou legislação. As matérias-primas constituem o material básico para a elaboração de alimentos de qualidade, logo devem ser cuidadosamente selecionadas. Toda matéria-prima deve ser submetida a inspeção e aprovada na recepção (SILVA et al., 2015). A temperatura deve ser verificada na recepção e no armazenamento, também deve-se conferir a rotulagem, na qual devem constar as informações do produto, bem como o prazo de validade. É necessário que esses processos sejam registrados em planilhas, datados e rubricados, visto que esses registros são requisitos importantes para controle e comprovação dos processos e rotinas de um estabelecimento (BRASIL, 2004).

O item 8 da tabela 1 (Preparação do alimento) foi o que apresentou a maior porcentagem de não conformidades, chegando a 73,1\% no restaurante RB e 61,5\% no RA. Durante a preparação dos alimentos, devem ser adotadas medidas, a fim de minimizar o risco de contaminação cruzada. Deve-se evitar o contato direto ou indireto entre alimentos crus, semipreparados e prontos para o consumo (MARIANO; MOURA, 2008).

Dentre as não conformidades foi encontrado o armazenamento de matérias-primas e alimentos prontos para o consumo armazenados em um mesmo equipamento de forma desorganizada e sem controle de temperatura. Observou-se inadequações no processo de higienização dos hortifrutigranjeiros, através do qual os colaboradores não seguiam as orientações do fabricante e mostraram-se em dúvidas quando questionados sobre a quantidade de cloro e volume de água utilizados. Quanto à utilização de ovos, o restaurante RB não obedecia aos critérios exigidos pela Portaria 78/2009 - RS (RIO GRANDE DO SUL, 2009). Outro procedimento que demonstrou falhas foi o resfriamento, que deve ser feito de $60^{\circ} \mathrm{C}$ para $10^{\circ} \mathrm{C}$, em no máximo 2 horas; embora ambos os restaurantes apresentavam equipamentos para um adequado resfriamento, não havia controle e monitoramento da temperatura. Ambos os restaurantes coletavam amostras de todos os itens do cardápio e as mantinham armazenadas em refrigeração por 72 horas, conforme exigido pela legislação.

O item 9 da tabela 1 (Armazenamento e transporte do alimento preparado) não se aplicava aos estabelecimentos pesquisados, visto que os mesmos servem apenas refeições no local.

No tocante ao item 10 da tabela 1 (Exposição ao consumo do alimento preparado), ambos os estabelecimentos apresentavam área de exposição e refeitório organizados, em boas condições de higiene e ausência de ornamentos que configurassem fontes de contaminação aos alimentos. Porém não havia registros do controle de temperatura e, no RB, os pratos e talheres se encontravam armazenados em local exposto. O tempo e a temperatura devem ser controlados e são imprescindíveis para a segurança microbiológica dos alimentos; muitos restaurantes comerciais deixam os alimentos expostos em balcões ou bancadas térmicas que deveriam ser mantidas a temperaturas acima de $60^{\circ} \mathrm{C}$, durante no máximo 6 horas (GERMANO; GERMANO, 2003). A temperatura e o tempo de exposição dos alimentos são importantes fatores de controle da multiplicação microbiana (BAS et al., 2006). 
Já em relação aos itens 11 e 12 da tabela 1 (respectivamente: Documentação e registros; Responsabilidade Técnica), em ambos os estabelecimentos, foi verificado um total de $100 \%$ de não conformidades, pois não havia registros de nenhuma atividade realizada. Os restaurantes não apresentavam Manual de Boas Práticas nem Procedimento Operacional Padronizado (POP) e os responsáveis pelos estabelecimentos demonstraram não ter conhecimento do assunto. Também não eram realizadas capacitações aos manipuladores dos alimentos e não havia um responsável técnico nos restaurantes.

O Manual de Boas Práticas é um documento no qual são descritos os procedimentos referentes às Boas Práticas de Fabricação realizadas em um serviço de alimentação, ele deve possuir conceitos e orientações úteis aos manipuladores, devendo estar disponível às pessoas que trabalham na produção e distribuição dos alimentos. Os Procedimentos Operacionais Padronizados (POP) devem conter instruções sequenciais das operações e a frequência de execução, especificando o nome, o cargo e/ou função dos responsáveis pelas atividades. Devem ser aprovados, datados e assinados pelo responsável do estabelecimento (BRASIL, 2004).

O panorama sanitário, segundo a Portaria $n^{\circ} 275$, apresentou-se muito inadequado. Avaliando os 12 grupos de verificação, foi encontrado um percentual de adequação geral muito baixo, de 34,21\% no restaurante RA e $32,86 \%$ no restaurante RB, sendo ambos os estabelecimentos classificados como deficientes, pertencentes, portanto, ao grupo 3.

\section{CONCLUSÃO}

De acordo com a lista de verificação aplicada, a classificação de ambos os restaurantes comerciais foi insatisfatória para a produção de alimentos seguros. Os estabelecimentos necessitam adequar-se aos itens considerados imprescindíveis, visando à qualidade de suas refeições e à saúde de seus clientes. Os resultados obtidos evidenciam extrema necessidade de modificação de diversos processos, em especial o que se refere à documentação e às responsabilidades. Nenhum dos doze itens avaliados atingiu o grupo 1, considerado bom, isso demonstra a necessidade de melhorias, tanto no que se refere à produção das refeições quanto à situação do estabelecimento perante as legislações vigentes. A adesão às boas práticas seria uma ferramenta viável para melhorar a qualidade das refeições produzidas pelo restaurante, garantindo um alimento seguro e sem risco de danos para a saúde do consumidor.

\section{REFERÊNCIAS}

AKUTSU, R. C. et al. Adequação das Boas Práticas de Fabricação em serviços de alimentação. Revista de Nutrição, v. 18, n. 3, p. 419-427, 2005. 
ALMEIDA, J. A. et al. Guia de verificação: boas práticas e APPCC. 2.ed. Brasília, DF: SENAI/DN, 2009. 70p.

ASSOCIAÇÃO BRASILEIRA DE REFEIÇÕES COLETIVAS (ABERC). Mercado Real. São Paulo. Disponível em: https://bit.ly/31p2CyQ. Acesso em: 07 jul 2019.

BAS, M. et al. The evaluation of food hygiene, knowledge, attitudes and practices of handlers in food businesses in Turkey. Food Control, v. 17, n. 4, p. 317-322, 2006.

BRASIL. Agência Nacional de Vigilância Sanitária. Resolução no. 275, de 21 de outubro de 2002. Regulamento técnico de procedimentos operacionais padronizados aplicados aos estabelecimentos produtores/industrializadores alimentos. Brasília, 2002.

BRASIL. Agência Nacional de Vigilância Sanitária. Resolução RDC no. 216, de 15 de setembro de 2004. Dispõe sobre regulamento técnico de boas práticas para serviços de alimentação. Brasília, 2004.

CONSELHO FEDERAL DE NUTRICIONISTAS (CFN). Resolução CFN n. 380/2005. Dispõe sobre a definição das áreas de atuação do nutricionista e suas atribuições, estabelece parâmetros numéricos de referência, por área de atuação e dá outras providências. CFN, 2005.

GENTA, T. M. S. et al. Avaliação das boas práticas através de check-list aplicado em restaurantes self-service da região central de Maringá, Estado do Paraná. Acta Science, v. 27, n. 2, p. 151-156, 2005.

GERMANO, P. M. L.; GERMANO, M.I.S. Higiene e Vigilância Sanitária dos Alimentos. São Paulo: Varela. 2003. 629p.

LEHTO, M. et al. Hygienic level and surface contamination in fresh-cut vegetable production plants. Food Control, v. 22, n. 4, p. 469-475, 2011.

LUES, J. F. R.; TONDER, I. V. The occurrence of indicator bacteria on hands and aprons of food handlers in the delicatessen sections of a retail group. Food Control, v. 18, n. 4, p. 326-332, 2007.

MARCHI, D. M. et al. Ocorrência de Surtos de Doenças Transmitidas por Alimentos no Município de Chapecó, Estado de Santa Catarina, Brasil, no período de 1995 a 2007. Epidemiologia e Serviços de Saúde, v. 20, n. 3, p. 401-407, 2011. 
MARIANO, C. G.; MOURA, P. N. Avaliação das Boas Práticas de Fabricação em unidade produtora de refeições (UPR) autogestão do interior do estado de São Paulo. Revista Salus, v. 2, n. 2, 2008.

MELLO, J. F. et al. Avaliação das condições de higiene e da adequação às boas práticas em unidades de alimentação e nutrição no município de Porto Alegre - RS. Revista Alimentos e Nutrição, v. 24, n. 2, p. 175-182, 2013.

MICHELINA, A. F. et al. Qualidade microbiológica de águas de sistemas de abastecimento público na região de Araçatuba, SP. Higiene Alimentar, v. 20, n.147, p. 90-95, 2006.

PROENÇA, R. P. C. et al. Qualidade Nutricional e Sensorial na Produção de Refeições. Florianópolis: Ed. UFSC, 2005.

RIO GRANDE DO SUL. Portaria $\mathbf{n}^{\mathbf{0}} \mathbf{7 8}$, de 28 de janeiro de 2009. Aprova a lista de verificação em boas práticas para serviços de alimentação, aprova normas para cursos de capacitação em boas práticas para serviços de alimentação e dá outras providencias. Porto Alegre, 2009.

SACCOL, A. L. F. et al. Avaliação das boas práticas em duas visões: técnica e da empresa. Brazilian Journal of Food Technology, v. 21, n. 2, p. 19-23, 2009.

SILVA, L. C. et al. Boas práticas na manipulação de alimentos em Unidades de Alimentação e Nutrição. Demetra, v. 10, n. 4, p. 797-820, 2015.

TONDO, E. C.; BARTZ, S. Microbiologia e Sistemas de Gestão da Segurança de Alimentos. Porto Alegre: Ed. Sulina, 2014.

ZANDONADI, R. P. et al. Atitudes de risco do consumidor em restaurantes de auto-serviço. Revista de Nutrição, v. 20, n. 1, p. 19-26, 2007. 